www.jmscr.igmpublication.org

Impact Factor (SJIF): 6.379

Index Copernicus Value: 71.58

ISSN (e)-2347-176x ISSN (p) 2455-0450

crossrefDOI: https://dx.doi.org/10.18535/jmscr/v6i6.83

Journal Of Medical Science And Clinical Research

IGM Publication

An official Publication of IGM Publication

\title{
Original Research Article \\ Morphometry of Human Cadaveric Spleen: An Institutional Study in the Population of Odisha
}

\author{
Authors \\ Dr Rajashree Biswal ${ }^{1}$, Dr Dharma Niranjan Mishra ${ }^{2 *}$, Dr Rajib Kanchan ${ }^{3}$ \\ Prof (Dr) Chinmayi Mohapatra ${ }^{4 *}$ \\ ${ }^{1}$ Associate Professor, Department of Anatomy SCB Medical College, Cuttack 753007 \\ ${ }^{2}$ Assistant professor, Department of Anatomy SCB Medical College, Cuttack 753007 \\ ${ }^{3}$ Senior resident, Department of Anatomy SCB Medical College, Cuttack 753007 \\ ${ }^{4}$ Professor, Department of Anatomy SCB Medical College, Cuttack. 753007. S.C.B Medical College Cuttack under \\ Utkal University \\ Corresponding Author \\ Dr Dharma Niranjan Mishra \\ Assistant Professor, Department of Anatomy SCB Medical College, Cuttack, India \\ Email: dharmaniranjan.mishra08@gmail.com, Mob 9937025361
}

\begin{abstract}
Introduction: Spleen is an important secondary lymphoid organ. Now a day's its immunological and haematological role in the body are well realised which enhances the clinical importance of spleen. As spleen shows a wide range of morphological variations in routine dissection classes for under graduate students warranted an understanding of splenic morphometry. The aim of the study is to find out different morphological variations of spleen in the population of Odisha with its clinical significances and comparison of the results with previous studies. Material and Methods: In the present study 50 human cadaveric spleens were taken. The shapes, poles, surfaces and borders of the spleen were observed. The Morphological features like length, breadth and width were measured by verniers calliper and weight of the spleen was being measured by electronic weighing balance.

Results: In the present study morphological variations were observed. The mean length of the spleen was $11.86 \mathrm{cmranges}$ from $8 \mathrm{~cm}$ to $14 \mathrm{~cm}$, the breadths of the spleen varied from $4 \mathrm{~cm}$ to $10 \mathrm{~cm}$ with an average breadth of $7.32 \mathrm{~cm}$ and the width of the spleen vary from $2 \mathrm{~cm}$ to $4.5 \mathrm{~cm}$ with mean of $3.07 \mathrm{~cm}$. The weight of the spleen shows a wide range of variations ranging from $25 \mathrm{grms}$ to $300 \mathrm{grms}$ with an average weight of $106.65 \mathrm{grms}$. Out of 50 spleens $(52 \%)$ were wedge shaped followed by tetrahedral (24\%) triangular (10\%), oval (8\%) and irregular (2\%).

Conclusions: A clear concept about the morphological variations of the spleen are very useful to the physician, surgeons and the radiologists to compare and rule out the pathological conditions involved in various diseases of spleen.

Keywords: Secondary lymphoid organ, immunological and haematological role.
\end{abstract}

\section{Introduction}

The spleen consists of a large encapsulated mass of vascular and lymphoid tissue. It is situated in the upper left quadrant of the abdominal cavity between fundus of stomach and the diaphragm. Spleen is an intraperitoneal organ with two surfaces namely diaphragmatic surface and visceral surface. It has superior and inferior 
borders and anterior and posterior poles or extremities $^{[1]}$. The diaphragmatic surface is smooth and convex and related to left dome of diaphragm. The visceral surface is irregular and marked by gastric, renal, pancreatic and colic impressions. The superior pole of spleen faces towards rounded vertebral column and anterior extremity or inferior pole is larger and less angulated faces laterally. The hilum of spleen is a long fissure pierced by the splenic vessels, nerves and lymphatics ${ }^{[1]}$. The weight and size of the spleen vary with age and sex in the same individual under different conditions. The average weight of spleen is about 150 grams with a wide normal range is between $80 \mathrm{~g}$ to $300 \mathrm{~g}$ depending on the amount of blood it contains ${ }^{[1,2]}$.

The spleen develops from both coelomic epithelium and from mesenchme of dorsal mesogastrium. During development several lobules form which fused with each other to form the spleen at later stage. In adult the notched superior border of spleen is a foot print of lobulated development of spleen in embryonic period $^{[2,6]}$. In human the spleen is involved in immunological response aginst blood borne antigen, removal of particulate matter and aged or defective blood cells from circulation. Spleen is also involved in Haemopoiesis of nomal fetus and adult with certain diseases ${ }^{[3]}$. There is a wide spread clinical importance of spleen due to its haematological and immunological role. The surge of enthusiasm for preserving damaged spleen came because of the fear of overwhelming post splenectomy infections (OPSI), which has highlighted the immunological role of spleen $^{[4]}$. The current trend of surgeons to preserve as much splenic tissue as possible where partial splenctomy is required ${ }^{[9]}$. So the aim of the study is to find out morphological variations of spleen in the population of odisha and its clinical significance and compare the result with previous studies.

\section{Materials and Methods}

In the present observational study was undertaken in the department of anatomy, SCB medical college, Cuttack, Odisha during routine dissection of abdomen and pelvis from 2015 to 2018. The spleens were removed from abdominal cavity by following standard dissection procedures. (2) they were washed with running tap water to clean the fatty tissue and debris. The numbering was done from 1 to 50 and detail morphological features of each spleen were studied carefully. Out of 50 spleens 31 were from male cadaver and only 19 belong to female and all the spleen were apparently healthy. We had excluded the damaged spleen. The shapes, Poles, borders, and surfaces of the each spleen were observed carefully. Lengths, breadths and widths were measured with the help of sliding caliiper in centimeters with $0.05 \%$ accuracy with the following parameters.

The length of the spleen was recorded as the greatest distance between two poles of the spleen.

The breadth was recorded as the greatest distance between two points at the same level on the superior and inferior borders.

The width was the greatest distances between diaphragmatic and visceral surfaces of the spleen.

The average weight of the spleen was taken with the help of electronic weighing balance.

Presence of splenic notches and fissures were also noted.

The data was obtained from the study was tabulated, statistically analyzed by Graph Pad Softwere and compared with previous studies.

\section{Results}

In the present study 50 cadaveric spleen were taken, out of them 26 (52\%) were wedge shaped and $15(30 \%)$ were tetrahedral [Table/Fig-1] and [Table/Fig-2]. The shapes like triangular, irregular and oval were $5(10 \%), 3(6 \%)$, and $1(2 \%)$ respectively [Table/Fig-1], [Table/Fig-3] and [Table/Fig-4]. 


\section{JMSCR Vol||06||Issue||06||Page 497-502||June}

Table/Fig-1]: Showing the shape of the spleen in percentage

\begin{tabular}{|l|c|c|c|}
\hline Serial nos & Shape of the spleen & No of specimens & Percentage (\%) \\
\hline 1 & Wedge shape & 26 & $52 \%$ \\
\hline 2 & Tetrahedral & 15 & $30 \%$ \\
\hline 3 & Triangular & 5 & $10 \%$ \\
\hline 4 & Irregular & 3 & $6 \%$ \\
\hline 5 & Oval & 1 & $2 \%$ \\
\hline
\end{tabular}
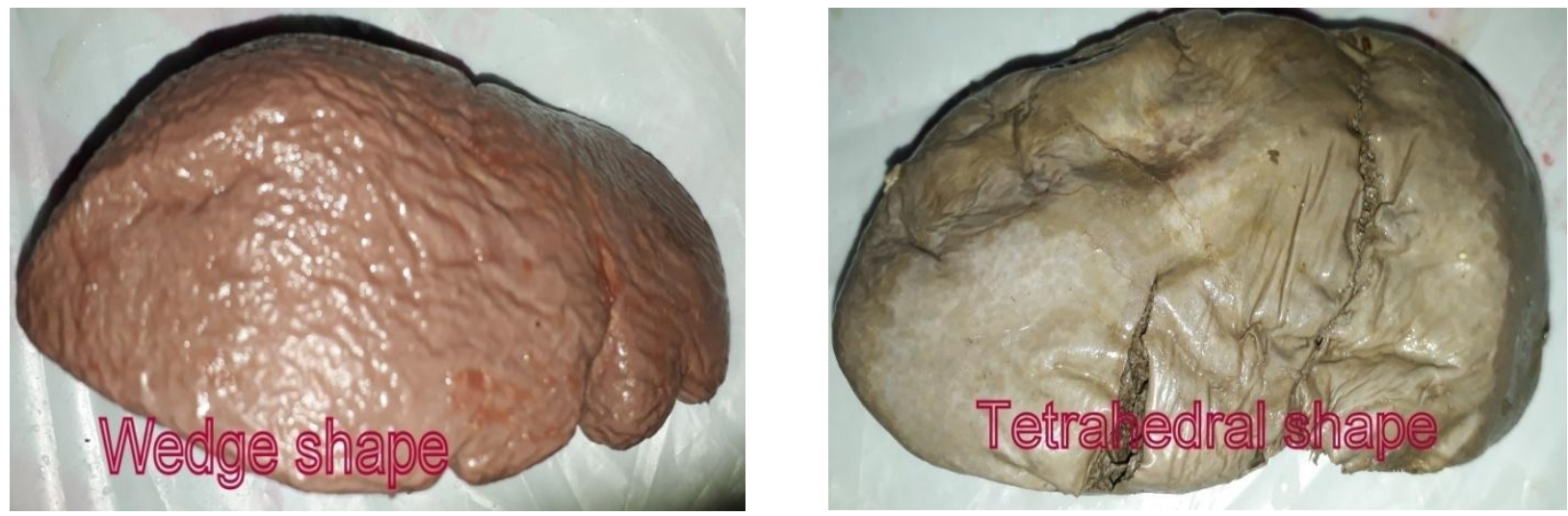

[Table/Fig-2]: Showing the shape of the spleen wedge and tetrahedral.
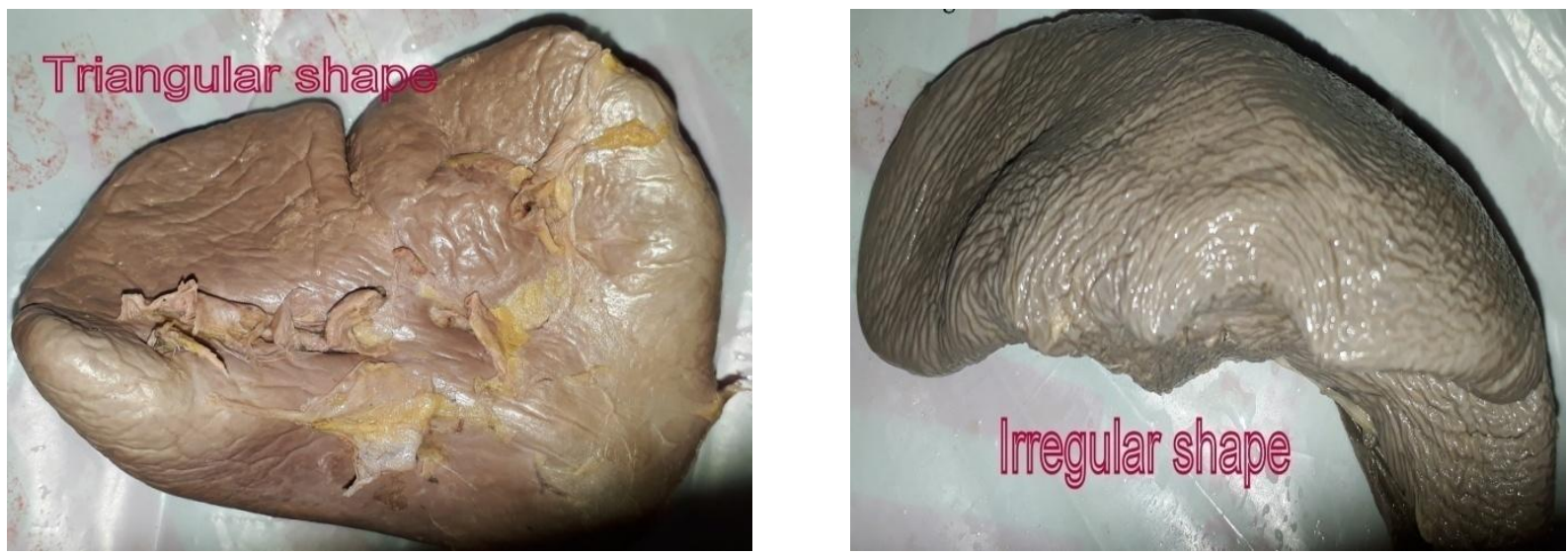

[Table/Fig-3]: Showing the shape of the spleen triangular and irregular

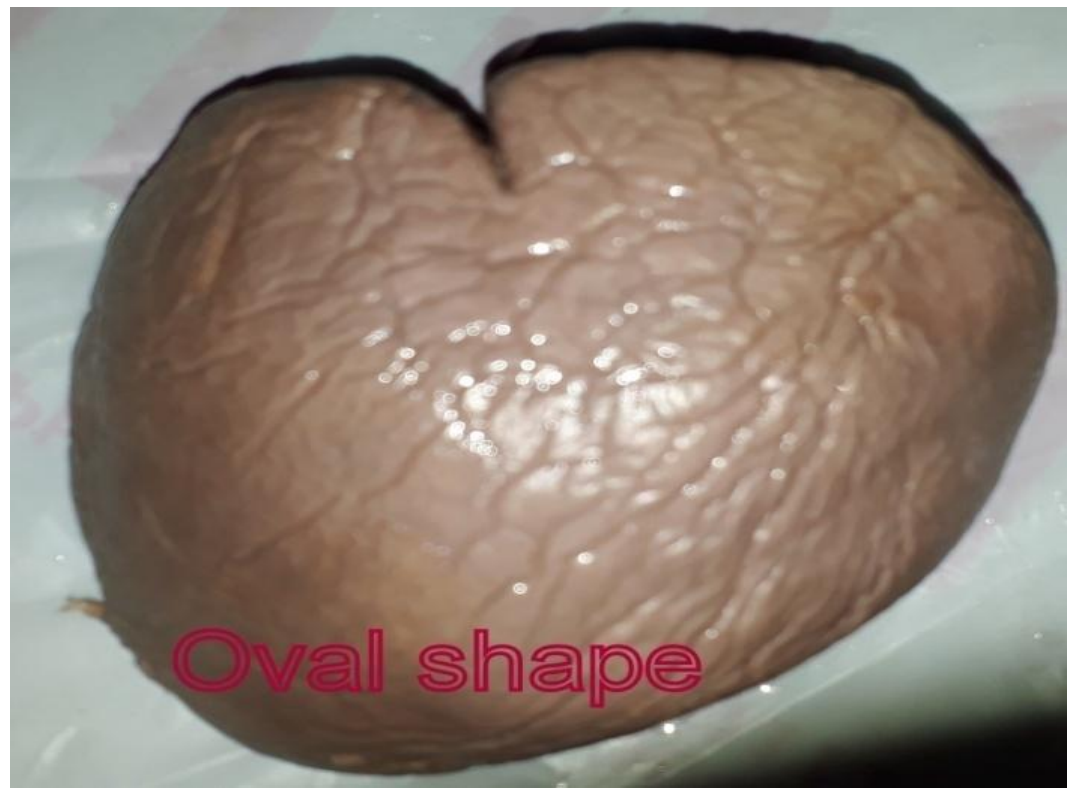

[Table/Fig-4]: Showing the shape of the spleen oval 
[Table/Fig-5]: Showing the variations of the weight of the spleen in the study specimens.

\begin{tabular}{|l|c|c|c|}
\hline Serial no & Weight of the spleen in grams & Number of spleen & Percentage \\
\hline 1 & $<50$ & 2 & $4 \%$ \\
\hline 2 & 50 to 100 & 23 & $46 \%$ \\
\hline 3 & 101 to 150 & 15 & $30 \%$ \\
\hline 4 & 151 to 200 & 7 & $14 \%$ \\
\hline 5 & 201 to 250 & 2 & $4 \%$ \\
\hline 6 & 251 to 300 & 1 & $3 \%$ \\
\hline
\end{tabular}

In the [Table/Fig-5] the mean weight of the spleens were 103.95 grams $(\mathrm{SD} \pm 51.26)$ ranges from 25.14 to 300 grams and most of the There were 10(20\%) specimens above 150 grams and only two specimens were below 50 grams constituting2 ( $4 \%$ ) of the total[Table/Fig-5]. specimens $38(76 \%)$ were between 50 to $150 \mathrm{gms}$.

[Table/Fig-6]: Showing the variations in length of the spleen in the study specimens.

\begin{tabular}{|l|c|c|c|}
\hline Serial no & Length of spleen in cms & Number of spleen & Percentage(\%) \\
\hline 1 & 7 to 9 & 4 & $8 \%$ \\
\hline 2 & 9.1 to 11 & 20 & $40 \%$ \\
\hline 3 & 11.1 to 13 & 20 & $40 \%$ \\
\hline 4 & $>13$ & 6 & $12 \%$ \\
\hline
\end{tabular}

The length of the spleens in present study varied between $7 \mathrm{~cm}$ to $14 \mathrm{~cm}$ with an average length of $11.92 \pm 2.14$ centimetres, however in most of the spleens 40 specimens ( $80 \%$ ) had the length ranges from $9 \mathrm{~cm}$ to $13 \mathrm{~cm}$ followed by $6(12 \%)$ specimen had more than 13 centimetres and $4(8 \%)$ cases were between 7 to 9 centimetres[Table/Fig$6]$.

[Table/Fig-7]: Showing the variations in breadth of the spleen in the study specimens

\begin{tabular}{|l|c|c|c|}
\hline Serial no & Beradth of spleen in cms & Number of spleen & Percentage (\%) \\
\hline 1 & 4 to 6 & 13 & $26 \%$ \\
\hline 2 & 6.1 to 8 & 27 & $54 \%$ \\
\hline 3 & 8.1 to 10 & 6 & $12 \%$ \\
\hline 4 & $>10$ & 4 & $8 \%$ \\
\hline
\end{tabular}

The observed mean breadth was $7.08 \mathrm{~cm} \pm 1.66$ cms followed by 13(26\%) specimens between 4 to ranges $4 \mathrm{cms}$ to $12 \mathrm{cms}$. Maximum breadth were 6 centimetres and $10(20 \%)$ specimens between seen in $27(54 \%)$ specimens ranges $6.1 \mathrm{cms}$ to 8 8.1 to 12 centimetres[Table/Fig-7].

[Table/Fig-8]: Showing the variations in width of the spleen in the study spcimens

\begin{tabular}{|l|c|c|c|}
\hline Serial no & Thickness in cms & No of specimen & Percentage \\
\hline 1 & 2 to 4 & 20 & $40 \%$ \\
\hline 2 & 4.1 to 6 & 28 & $56 \%$ \\
\hline 3 & $>6$ & 2 & $4 \%$ \\
\hline
\end{tabular}

In the present study the mean width was $3.08 \pm$ $0.66 \mathrm{cms}$ ranges $4 \mathrm{~cm}$ to $12 \mathrm{~cm}$. Maximum specimens $28(56 \%)$ were between $4 \mathrm{~cm}$ to $6 \mathrm{~cm}$

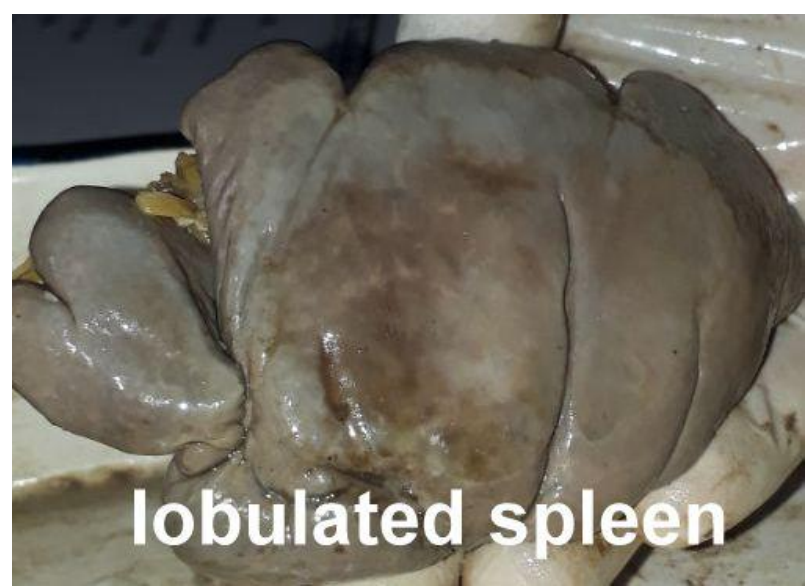

[Table/Fig-9]: Showing the spleens having fissures. followed by 20(40\%) cases 2 to 4 centimetres and onle $2(4 \%)$ specimens had breadth more than 6 centimetres[Table/Fig-8].

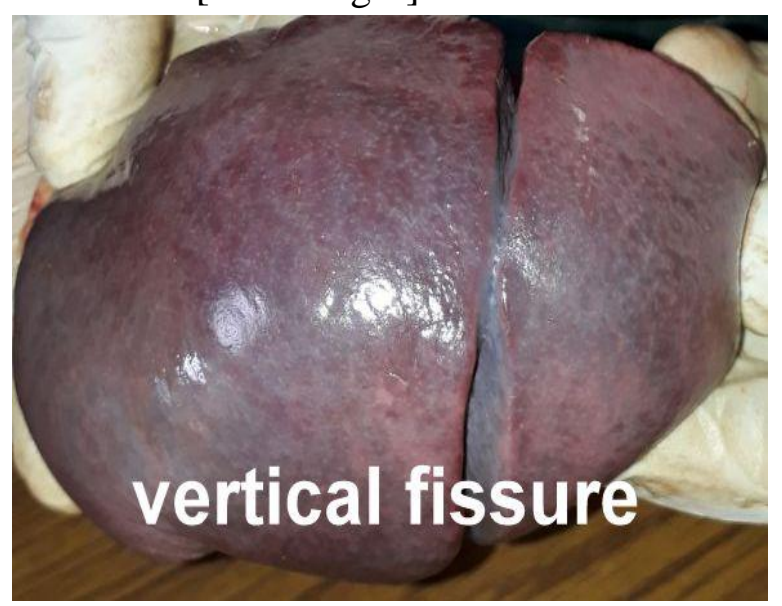


The typical lobulated appearance of spleen was seen in $2(4 \%)$ specimens in the present study. The lobulations were due to linear and oblique fissures present on the spleen [Table/Fig-9]. The number of spleen showing notches in the superior border were found to be $25(50 \%)$ inferior border $4(8 \%)$ and both the borders was 21(42\%).

\section{Discussion}

Many variations in the morphology of spleen are mentioned in Gray"s anatomy and also reported by other Authors like Hollinshead and Michel ${ }^{[1,7]}$.
The shape of the spleen varies from wedge to a domed" tetrahedron, the shape mostly determined by its relations to neighbouring structures during development and fusion of multiple speniculi ${ }^{[1]}$. In the present study we observed different shapes of spleen out of which wedge shaped $26(52 \%)$ was found to be most common, followed by tetrahedral, triangular, irregular and. oval. The percentage of different shapes of spleen differ from Rao et al and hollinshed but very close to Chaware et al. ${ }^{[5,8,10]}$

[Table/Fig-10]: Showing the Variations in shapes of spleen

\begin{tabular}{|l|c|c|c|c|}
\hline Shape of spleen & Rao et. al.2013 & $\begin{array}{c}\text { Hollinshed WH 1986 } \\
{[6]}\end{array}$ & $\begin{array}{c}\text { Chaware et. al. } \\
2012^{[10]}\end{array}$ & Present study \\
\hline wedge & $40 \%$ & $44 \%$ & $61.26 \%$ & $52 \%$ \\
\hline tetrahedral & $20 \%$ & $14 \%$ & $21.63 \%$ & $30 \%$ \\
\hline triangular & $32 \%$ & $42 \%$ & $12.61 \%$ & $10 \%$ \\
\hline irregular & 00 & 00 & $0,90 \%$ & $6 \%$ \\
\hline oval & $8 \%$ & 00 & $3,60 \%$ & $2 \%$ \\
\hline
\end{tabular}

In the present study different dimensions of spleens were similar to previous studies. The length of the spleen varied from $8 \mathrm{~cm}$ to $14 \mathrm{~cm}$ with a average length of $11.86 \mathrm{~cm}$, the breadth varied from $4 \mathrm{~cm}$ to $10 \mathrm{~cm}$ with an average of $7.32 \mathrm{~cm}$ and width ranges from $2 \mathrm{~cm}$ to $4.5 \mathrm{~cm}$ with an average width of $3.07 \mathrm{cms}$ The mean value of length, breadth. and width of the spleen in present study were $11.88 \mathrm{~cm}, 7.32 \mathrm{~cm}, 3.07 \mathrm{~cm}$ respectively. ${ }^{[1,7}$, $8,10]$

[Table/Fig-11]: Showing the Comparison of the dimensions of spleens with previous authors

\begin{tabular}{|l|c|c|c|c|c|}
\hline Measurement & $\begin{array}{c}\text { Michael et.al. } \\
1942^{[7]}\end{array}$ & $\begin{array}{c}\text { Rao et. al. 2013 } \\
{[8]}\end{array}$ & $\begin{array}{c}\text { Chaware e.t al. } \\
2012^{[10]}\end{array}$ & $\begin{array}{c}\text { Text book of } \\
\text { Gray 41 }^{\text {th }} \operatorname{Edn}^{[1]}\end{array}$ & Present study \\
\hline Length & 11 & 10.5 & 9.66 & 12 & 11.86 \\
\hline breadth & 7 & 8.3 & 6.22 & 7 & 7.33 \\
\hline Width & 3 & 00 & 3.06 & 3 to 4 & 3.07 \\
\hline
\end{tabular}

In the present study weight of the spleen varied between 50 grams to 300 grams with an average weight of 106 grams and in two specimens weight was less than 50 grams. Which appear lower than the normal range 80 to 300 grams with an average weight of 150 grams reported by previous studies $(1,6)$ this may be due to differences in socio economic status, feeding habits, geographical conditions in the population of odisha. The splenic notches were found in superior and inferior borders. The average number of splenic notches were seen as one or two ranges from 0 to 4 . In the superior border $25(50 \%)$, inferior border $4(8 \%)$ and both the borders $21(42 \%)$ were observed, which is similar to Nayak BS et.al.2011 ${ }^{[11]}$. There were two specimens having deep fissures giving appearance of lobulated speen.

\section{Conclusion}

The morphometric anatomical variations of spleen may be helpful for the physician to access the progression of certain diseases process and surgeons for proper diagnosis before planning for cases of partial or total splenectomy. As the immune response plays a vital role in the body defence mechanism it is mandatory to preserve the spleen as far as possible during surgery. This knowledge will be helpful to the radiological 
diagnosis of dieses related to spleen and last but not the least to the first year MBBS students in their classroom dissections.

Conflict of interest: None to declare

\section{References}

1. Standring S: Gray's Anatomy: The Anatomical Basis of the Clinical Practice, 41th edition. Edinburg: Elsevier Churchill Livingstone. 2016 ; 1188-1193.

2. Rachel Koshi, Cunningham's Manual of Practical Anatomy, Thorax and Abdomen. Sixteenth Edition. VOL 2, New York: Oxford University press; 2016:157.

3. Wheater's Functional Histology (5Th Edition);2006: 229-233.

4. Lee McGregor's Synopsis of Surgical Anatomy. $12^{\text {th }}$ edition. John Wright \& Sons Ltd. 1986; 107-113.

5. Hollinshead WH. Anatomy for Surgeons, 3rd ed. vol- 2. New York: Harper and Row. 1982; 436-45.

6. Endo A, Ueno S, Yamada $\mathrm{C}$ and Takakuwa T. Morphogenesis of the spleen during the human embryonic period.Anat Rec (Hoboken). 2015;298(5):820-6.

7. Michels NA. The variational Anatomy of the spleen and the splenic artery. Am J Anat Anatomy. 1942;70:21-72.

8. Rao S, Katikireddi S. Morphometric study of human spleen. Int $\mathbf{J}$ Biol Med Res 2013;4:3464-8.

9. Brigden ML, Pattullo AL. Prevention and management of overwhelming post splenectomy infection: an update. Crit Care Med 1999; 27: 836-842.

10. Chaware PN, Belsare SM, Kulkarni YR, Sudhir Vishnupant, Ughade JM. The Morphological Variations. J ClinDiagn Res 2012; 6: 159-62.

11. Nayak BS, Somayajiand SN, soumya KV. A Study on the Variations of Size, Shape and External Features of the Spleen in
South Indian Population. Int J Morphol. 2011; 29(3): 675-677. 